DOI: $10.7454 /$ jki.v21i3.773

\title{
MODEL KEPEMIMPINAN SERVANT PALING DOMINAN BERHUBUNGAN DENGAN KINERJA
}

\author{
Lilis Rayatin ${ }^{1 *}$, Enie Novieastari ${ }^{2}$, Efy Afifah $^{2}$ \\ 1. Harapan Kita Children and Women's Hospital, Jakarta 11420, Indonesia \\ 2. Faculty of Nursing Universitas Indonesia, Depok 16424, Indonesia \\ *E-mail: raya.fikui@gmail.com
}

\begin{abstract}
Abstrak
Model kepemimpinan kepala ruangan dapat meningkatkan kinerja perawat pelaksana dalam memberikan asuhan keperawatan. Tujuan penelitian ini adalah untuk mengidentifikasi hubungan antara model kepemimpinan kepala ruangan dengan kinerja perawat pelaksana. Metode penelitian menggunakan cross sectional, dengan melibatkan 141 responden di sebuah RS. Instrumen yang digunakan adalah instrumen model kepemimpinan yang pernah digunakan sebelumnya. Model kepemimpinan yang berhubungan dengan kinerja adalah servant, visioner, dan transaksional. Model kepemimpinan yang paling dominan berhubungan dengan kinerja adalah servant $(p=0,0001 ; \alpha=0,05 ; C I$ : 2,733-11,853; Odd Ratio: 5,691). Kepala ruangan yang dipersepsikan oleh perawat pelaksana menggunakan model kepemimpinan servant berpeluang meningkatkan kinerja perawat pelaksana sebesar 5 kali lebih tinggi dibandingkan dengan yang tidak dipersepsikan menggunakan model kepemimpinan servant. Hasil penelitian ini merekomendasikan kepada pimpinan Rumah sakit khususnya untuk kepala ruangan dapat menggunakan model kepemimpinan servant dalam peran dan fungsinya untuk meningkatkan kinerja perawat pelaksana.
\end{abstract}

Kata kunci: Kinerja perawat pelaksana, Model kepemimpinan servant.

\begin{abstract}
Head Nurse Leadership Model Can Improve The Performance of Nurses in Providing Nursing Care. The purpose of this study was to identify the correlation between the head nurse leadership model and the nurses' performance. This study applied a cross-sectional method and involved 141 nurses at a Hospital. This study used the instruments was developed in the other studies. The results showed that the leadership model related to the performance was a servant, visionary, and transactional. The most dominant leadership model related to the performance was servant ( $p=0.0001$; $\alpha=0.05$, CI: 2.733 to 11.853; odds ratio: 5.691). Head nurses that were perceived by nurses as using the servant leadership model had an opportunity to improve the nurses' performance five times higher than those who were not perceived as using the servant leadership model. It is recommended that the head of Hospitals, especially the head nurses, to apply the servant leadership model in their roles and functions to improve the nurses' performance.
\end{abstract}

Keywords: Nurses' performance, Servant Leadership model

\section{Pendahuluan}

Semua bidang bersaing di era globalisasi untuk meningkatkan mutu dan daya saingnya agar dapat memuaskan pelanggan. Pesatnya kemajuan ilmu pengetahuan dan teknologi di segala bidang berdampak pada semakin tingginya kualitas pelayanan (Fitrihana, 2011). Rumah sakit agar selalu tanggap akan perubahan-perubahan yang terjadi dengan cepat, dan segera mengantisipasinya sesuai dengan keinginan dan kebutuhan masyarakat serta selalu memuaskan konsumen/ Customer satisfaction (Ahmad, 2012). Sikap karyawan yang positif terhadap pemimpin, dan lingkungan kerja mempunyai hasil yang signifikan untuk meningkatkan kepuasan pelanggan dan keuntungan organisasi (WilchesAlzate, 2009). 
Kinerja perawat perlu diteliti karena hasil kerja perawat merupakan salah satu indikator mutu rumah sakit. Kinerja perawat yang baik dapat meningkatkan mutu pelayanan rumah sakit sehingga memberikan kepuasan kepada pelanggan. Kompetensi karyawan berupa kinerja yang baik dapat mendorong tercapainya tujuan organisasi (Robert \& John, 2006). Karyawan dituntut untuk bekerja dengan baik sesuai dengan tugasnya sehingga memberikan hasil kerja yang terbaik bagi perusahaan (Oei, 2005). Perawat profesional adalah sumber daya yang paling penting di rumah sakit oleh karena itu kompensasi berbasis kinerja yang sesuai untuk pelayanan keperawatan merupakan hal yang prioritas (Mamikhani, Tofighi, Sadeghifar, Heydari, \& Jenab, 2014).

Rumah sakit di Indonesia semakin banyak tuntutan masyarakat terhadap pelayanan khususnya keperawatan semakin tinggi, maka manajemen keperawatan segera berubah, guna meningkatkan mutu pelayanannya. Beberapa model yang telah dikembangkan dan diterapkan di luar negeri dan telah diteliti di Indonesia (Robbins, \& Judge 2013; Yuswanto, 2013). Penelitian oleh Yasman (2013) dan Yuswanto (2013) tentang model kepemimpinan keperawatan yang dibangun, secara positif didukung oleh model kepemimpinan servant, visioner, situasional, transaksional, transformasional, beserta elemen-elemennya.

Beberapa penelitian mengatakan bahwa kepemimpinan memberi pengaruh terhadap kinerja karyawannya. Hasil penelitian yang dilakukan oleh Didimus, Indar, dan Hamzah (2013) didapatkan salah satu faktor yang berhubungan dengan kinerja perawat adalah kepemimpinan. Penelitian Natalia (2010) memaparkan bahwa model kepemimpinan diwakili oleh kepemimpinan transformasional memengaruhi kinerja waktu proyek. Penelitian yang dilakukan oleh Kieu (2010) menemukan bahwa kepemimpinan adalah salah satu kontributor paling signifikan untuk kinerja organisasi. Analisis regresi logistik menunjukkan bahwa hubungan yang signifikan antara gaya kepemimpinan dan ki- nerja organisasi di sebuah perusahaan komunikasi di Amerika Serikat (Kieu, 2010).

Penelitian terdahulu tentang model kepemimpinan kepala ruangan belum dikaitkan dengan kinerja. Melalui penelitian ini dengan metoda cross sectional diharapkan dapat teridentifikasi model kepemimpinan yang paling dominan berhubungan meningkatkan kinerja perawat pelaksana rumah sakit. Prestasi kerja berkorelasi positif dengan komitmen organisasi, kepuasan kerja, profesional, dan variabel pribadi (AlAhmadi, 2009). Rumah sakit tidak dapat sukses dan makmur tanpa evaluasi perawat oleh pemimpin yang efektif (Hewison \& Griffiths, 2004).

Penelitian ini bertujuan untuk mengidentifikasi hubungan persepsi perawat pelaksana tentang model kepemimpinan kepala ruangan dengan kinerja perawat pelaksana di salah satu Rumah Sakit di Jakarta.

\section{Metode}

Penelitian cross sectional, jumlah sampel dengan total sampling yang berjumlah 141 orang. Cara pengambilan sampel dengan menggunakan instrumen kuesioner kepada responden. Analisis data dengan univariat, bivariat, dan multivariat. Proses penelitian ini dilakukan selama 9 hari dari 21 - 29 April 2014 di sebuah rumah sakit di Jakarta Barat. Persetujuan etik didapatkan dari komite etik FIK UI. Penelitian ini menerapkan prinsip etik dengan menghormati harkat dan martabat manusia.

Kriteria inklusi sampel mencakup perawat pelaksana yang bertugas di ruang rawat yang melaksanakan asuhan keperawatan berdasarkan pendekatan proses keperawatan, berpendidikan diploma tiga keperawatan atau Kebidanan atau Gigi, diploma empat Kebidanan atau Gigi dan Sarjana keperawatan (Ners) atau Kebidanan, lama kerja di rumah sakit minimal setahun. Kriteria eksklusi adalah perawat ketua tim, clinical instructor, kepala ruangan, pengelola urusan, kepala seksi, kepala bidang keperawatan, 
dan tenaga keperawatan yang tidak memberikan asuhan keperawatan, serta perawat yang sedang sakit, sedang cuti, atau sedang tugas belajar pada saat dilakukan penelitian.

Kuesioner A berisi tentang data demografi perawat berdasarkan Robbins dan Judge (2013), dan Sitanggang (2010) yang dikembangkan oleh peneliti dan merupakan data langsung yang diperoleh dari responden. Data demografi terdiri dari usia, tingkat pendidikan, status perkawinan, dan lama kerja. Kuesioner B berisi tentang model kepemimpinan kepala ruangan. Model kepemimpinan sesuai penelitian oleh Yasman (2013) dengan modifikasi penambahan pernyataan negatifnya dari tiga item menjadi 20 item. Instrumen meliputi elemen model kepemimpinan servant, model kepemimpinan visioner, model kepemimpinan situasional, model kepemimpinan transaksional, dan model kepemimpinan transformasional.

Kuesioner C merupakan kuesioner kinerja perawat pelaksana. Komponen kinerja yang terdiri dari: hubungan dengan pasien dan keluarga, hubungan dengan rekan kerja, keselamatan pasien, penampilan, ketaatan, dan pengembangan diri. Kuesioner ini dikembangkan oleh peneliti dengan menggabungkan dari referensi
Bidang Keperawatan Rumah Sakit Anak dan Bunda Harapan Kita (2014), Ilyas (2012), Kementerian Kesehatan RI (2013a), Kementerian Kesehatan RI (2013b), Kuspriyomurdono (2012), dan Sari (2009).

Uji validitas dan reliabilitas dengan nilai $r$ tabel 0,361. Hasil Uji validitas kuesioner B dan $\mathrm{C}$ diperoleh rerata $\mathrm{r}=0,563$. Uji reliabilitas instrumen ini dengan Croncbach Alpha reliabilitas 0,971 .

\section{Hasil}

Hasil analisis karakteristik perawat pelaksana di Rumah Sakit X pada Tabel 1 menunjukkan bahwa dari sejumlah 141 perawat pelaksana sebagian besar berusia 34 tahun atau lebih (51, $1 \%)$, perempuan $(95,7 \%)$, pendidikan vokasional $(90,1 \%)$, status menikah $(89,4 \%)$, dan lama kerja minimal 11 tahun $(51,1 \%)$. Usia terendah 24 tahun dan tertinggi 56 tahun. Lama kerja terendah setahun dan tertinggi 38 tahun.

Kinerja perawat pelaksana menunjukkan bahwa $83(58,9 \%)$ berkinerja baik. Hasil analisis model kepemimpinan kepala ruangan di rumah sakit menunjukkan bahwa kepala ruangan dominan menggunakan model kepemimpinan trans

Tabel 1. Karakteristik Perawat Pelaksana Berdasarkan Umur, Jenis Kelamin, Pendidikan, Status Perkawinan, dan Lama Kerja

\begin{tabular}{lcc}
\hline & Karakteristik & \multicolumn{2}{c}{ Distribusi Frekuensi } \\
\cline { 2 - 3 } & $\mathrm{N}$ & $\%$ \\
\hline Usia & 69 & 48,9 \\
$<34$ & 72 & 51,1 \\
$\quad \geq 34$ & \multicolumn{2}{c}{} \\
Jenis kelamin & 6 & 4,3 \\
$\quad$ Laki-laki & 135 & 95,7 \\
$\quad$ Perempuan & 127 & 90,1 \\
Pendidikan & 14 & 9,9 \\
$\quad$ Vokasional & & 10,6 \\
$\quad$ Profesional & 15 & 89,4 \\
Status perkawinan & 126 & 48,9 \\
$\quad$ Belum kawin & & 51,1 \\
$\quad$ Kawin & 69 & \\
Lama Kerja & 72 & \\
$\quad<11$ & & \\
$\geq 11$ & &
\end{tabular}


Tabel 2. Hubungan Model Kepemimpinan Kepala Ruangan dengan Kinerja Perawat Pelaksana

\begin{tabular}{|c|c|c|c|c|c|c|}
\hline \multirow{3}{*}{ Model Kepemimpinan } & \multicolumn{4}{|c|}{ Kinerja } & \multirow{3}{*}{ OR } & \multirow{3}{*}{$\mathrm{p}$} \\
\hline & \multicolumn{2}{|c|}{ Baik } & \multicolumn{2}{|c|}{ Kurang } & & \\
\hline & $\mathrm{n}$ & $\%$ & $\mathrm{n}$ & $\%$ & & \\
\hline Servant & & & & & 5,691 & $0,0001^{*}$ \\
\hline Digunakan & 61 & 76,3 & 19 & 23,8 & & \\
\hline Tidak digunakan & 22 & 36,1 & 39 & 63,9 & & \\
\hline Visioner & & & & & 5,579 & $0,0001^{*}$ \\
\hline Digunakan & 68 & 72,3 & 26 & 27,7 & & \\
\hline Tidak digunakan & 15 & 31,9 & 32 & 68,1 & & \\
\hline Situasional & & & & & 1,294 & 0,605 \\
\hline Digunakan & 59 & 60,8 & 38 & 39,2 & & \\
\hline Tidak digunakan & 24 & 54,5 & 20 & 45,5 & & \\
\hline Transaksional & & & & & 3,150 & $0,003 *$ \\
\hline Digunakan & 63 & 68,5 & 29 & 31,5 & & \\
\hline Tidak digunakan & 20 & 40,8 & 29 & 59,2 & & \\
\hline Transformasional & & & & & 2,357 & $0,196^{*}$ \\
\hline Digunakan & 77 & 61,1 & 49 & 38,9 & & \\
\hline Tidak digunakan & 6 & 40,0 & 9 & 60,0 & & \\
\hline
\end{tabular}

*Bermakna pada $\alpha=0,05$

formasional $(89,4 \%)$, situasional $(68,8 \%)$, visioner $(66,7 \%)$, transaksional $(65,2 \%)$, dan servant $(56,7 \%)$.

Rerata usia perawat yang berkinerja baik adalah sama atau lebih dari 34 tahun $(62,5 \%)$. Hasil uji statistik didapatkan nilai $\mathrm{p}=0,49, \mathrm{p}>\alpha$ 0,05, maka dapat disimpulkan bahwa tidak ada hubungan antara usia dengan kinerja perawat pelaksana. Jenis kelamin perawat pelaksana yang memiliki kinerja baik yaitu Laki-laki $(83,3 \%)$ dengan nilai $\mathrm{p}=0,412, \mathrm{p}>\alpha 0,05$, maka dapat disimpulkan bahwa tidak ada hubungan yang signifikan antara jenis kelamin dengan kinerja perawat pelaksana.

Pendidikan keperawatan perawat rerata yang memiliki kinerja baik yaitu Vokasional (D3/ D4 Keperawatan, Kebidanan, Gigi) $(59,5 \%)$. Uji statistik menunjukkan nilai $\mathrm{p}=0,855, \mathrm{p}>\alpha$ 0,05, maka dapat disimpulkan bahwa tidak ada hubungan yang bermakna antara pendidikan dengan kinerja perawat pelaksana. Status perkawinan perawat rerata yang memiliki kinerja baik yaitu sudah kawin $(61,1 \%)$. Uji statistik menunjukkan nilai $\mathrm{p}=0,196, \mathrm{p}>\alpha 0,05$, maka dapat disimpulkan bahwa tidak ada hubungan yang bermakna antara status perkawinan de- ngan kinerja perawat pelaksana. Lama kerja perawat rerata yang memiliki kinerja baik adalah $\geq 11$ tahun $(63,9 \%)$. Hasil uji statistik yaitu nilai $\mathrm{p}=0,286, \mathrm{p}>\alpha 0,05$, maka dapat disimpulkan bahwa tidak ada hubungan yang bermakna antara lama kerja dengan kinerja perawat pelaksana.

Hasil analisis hubungan model kepemimpinan kepala ruangan dengan kinerja perawat pelaksana menurut persepsi perawat pelaksana di rumah sakit dapat dilihat pada tabel 2 .

Hasil analisis multivariat dari tahap awal sampai akhir menunjukkan bahwa variabel yang paling berhubungan secara bermakna dengan kinerja perawat adalah servant dengan nilai $\mathrm{p}=$ 0,0001. Hasil analisis menunjukkan bahwa kepala ruangan yang menggunakan model kepemimpinan servant cenderung meningkatkan kinerja perawat pelaksana. Hasil akhir analisis multivariat menunjukkan model kepemimpinan yang paling berhubungan dengan kinerja perawat pelaksana dengan mengacu kepada OR yang paling besar.

Servant memiliki OR 5,691, maka model kepemimpinan yang paling berhubungan adalah 
servant. Kepala ruangan yang dipersepsikan oleh perawat pelaksana menggunakan model kepemimpinan servant mempunyai OR 5,691 artinya berpeluang meningkatkan kinerja perawat pelaksana sebesar 5 kali lebih tinggi dibandingkan dengan yang tidak dipersepsikan menggunakan model kepemimpinan servant.

\section{Pembahasan}

Sebagian besar perawat pelaksana di RS tempat penelitian dilakukan berada pada usia mendekati dewasa tengah yaitu sekitar 40 sampai 60 tahun. Pada rentang usia ini sebagian besar berkinerja baik. Pada usia ini perawat merasa puas mencapai puncak karier. Kepala ruangan dapat mengantisipasinya dengan lebih tanggap terhada sumber stres seperti ketidakberhasilan mencapai apa yang dicita-citakan, kesalahpahaman. Pemberian reinforcement positif untuk memberikan reward atas upaya yang dilakukan merupakan hal yang penting dilakukan (Bastable, 2002). Beberapa perawat pelaksana sudah berusia 58 tahun dengan pendidikan D3 dan S1 Keperawatan, hal ini seharusnya menjadi perhatian. Pemimpin dan kepala ruangan perlu menata jenjang karir berdasarkan kinerja, kemampuan, dan minat dari perawat pelaksana, sehingga pada usia tengah akhir sudah memiliki posisi jenjang karir yang sesuai dengan harapan.

Robbins dan Judge (2013), perempuan lebih menyenangkan dan mudah beradaptasi dengan otoritas, laki-laki lebih agresif cenderung mengharapkan keberhasilan. Mengingat partisipasi perempuan meningkat pada 40 tahun terakhir, maka diasumsikan tidak ada perbedaan yang signifikan dalam kinerja antara laki-laki dan perempuan. Hasil penelitian ini sejalan dengan Setiawati (2010) tidak ada hubungan antara usia dengan kinerja.

Persepsi perawat pelaksana tentang kinerja baik pada pendidikan Profesional dimungkinkan mempunyai standar yang tinggi, sehingga perawat yang memiliki kinerja baik jumlahnya menjadi kurang. Perawat dengan pendidikan
S1 Keperawatan perlu terus ditingkatkan agar dapat memenuhi kualifikasi perawat klinik (PK) IV, memenuhi jabatan clinical instruct, dan kepala ruangan. Walaupun perbedaan kinerja baik perawat vokasional dan profesional sedikit tetap pendidikan profesional perlu ditingkatkan agar metoda asuhan keperawatan dengan primary nursing dapat berjalan lebih optimal di seluruh ruangan. Hal tersebut sesuai pendapat Ilyas (2012), bahwa semakin tinggi tingkat pendidikan seseorang, akan semakin logis, kritis, dan sistematis dalam berfikir dan bertindak, sehingga akan meningkatkan kualitas hasil kerja.

Perawat yang sebagian besar perempuan dan mempunyai anak usia pra sekolah diperlukan sistem pendukung support system sistem pendukung yang baik agar tumbuh kembangnya dapat optimal dan orang tua dapat bekerja dengan konsentrasi. Hasil penelitian ini sejalan dengan penelitian Sitanggang (2010), berbeda dengan penelitian Al-Ahmadi (2009).

Pengalaman kerja perawat di rumah sakit sebagian besar tergolong senior. Masa kerja ini diperlukan pendidikan dan pelatihan yang berkesinambungan agar diperoleh pengalaman kerja yang sebanding dengan peningkatan kinerja. Tappen (2004) menyatakan bahwa lama kerja yang tidak didukung pengembangan staf yang optimal akan menurunkan kualitas pekerjaannya. Perawat yang berpengalaman kerja lebih lama dapat menjadi mentor bagi perawat yang lebih junior, sehingga diharapkan dapat mencapai jenjang karir yang sesuai dengan harapan, dan mempunyai kinerja yang baik. Menurut peneliti tidak adanya hubungan lama kerja dengan kinerja dapat disebabkan masih kurang optimalnya pendidikan dan pelatihan perawat. Hasil penelitian ini sejalan dengan penelitian Setiawati (2010), berbeda halnya dengan hasil penelitian Al-Ahmadi (2009).

Pada penelitian ini didapatkan bahwa adanya hubungan antara kepemimpinan servant, visioner dan transaksional dengan kinerja perawat pelaksana. Penelitian Goleman, Boyatzis, dan 
Mckee (2007) menunjukkan bahwa pendekatan visioner merupakan model paling efektif untuk menggugah hati staf bahwa pekerjaan mereka ikut berperan dalam pencapaian visi organisasi. Transparansi sangat penting untuk dapat memiliki kredibilitas, pemimpin harus sungguh-sungguh meyakini akan keberhasilan visi organisasinya. Model ini cocok digunakan di salah satu rumah sakit di Jakarta yang memiliki perawat pelaksana hampir sebagian dengan lama kerja kurang dari 11 tahun. Model ini tidak cocok diterapkan pada situasi dimana stafnya yang sudah ahli atau sangat berpengalaman karena dianggap tidak sejalan dengan tugas yang ada sehingga akan berdampak kinerja kurang.

Model transaksional berpasangan dengan transformasional untuk memperoleh hasil yang optimal. Model ini cocok untuk kepemimpinan penjualan, perusahaan yang berorientasi pada bisnis. Heller (2008/2001), berkaitan dengan interaksi yang efisien dengan realitas yang selalu berubah, berfokus pada intisari dan kejadian. Model ini akan memberikan penghargaan tinggi bagi karyawan yang mempunyai kinerja tinggi dan memberi penghargaan kecil pada karyawan yang mempunyai kinerja kurang.

Model kepemimpinan servant menempati urutan pertama sebagai model kepemimpinan yang paling berhubungan dengan kinerja perawat pelaksana di rumah sakit. Kepala ruangan yang dipersepsikan menggunakan model kepemimpinan servant berpeluang untuk meningkatkan kinerja perawat pelaksana lima kali lebih besar dibandingkan dengan kepala ruangan yang tidak dipersepsikan menggunakan model kepemimpinan servant. Tokoh pemimpin servant seperti Umar Bin Khotob, Mahatma Gandhi, dan Nelson Mandela (Alfian, 2009).

Perawat pelaksana mengharapkan sosok pemimpin servant yang mampu mendengarkan keluhan staf, empati dengan staf, mempunyai kesadaran diri yang tinggi, dapat mengajak staf, mampu membuat konsep perencanaan yang baik, berwawasan ke depan, mampu mengem- bangkan staf, mampu mendorong staf untuk membangun kebersamaan, dan mampu membantu staf dalam menyelesaikan pekerjaan. Penelitian Mahembe dan Engelbrecht (2014), model kepemimpinan servant memainkan peranan penting dalam efektifitas organisasi, temuan menekankan peran kepemimpinan servant dalam mempromosikan perilaku positif dan hasil untuk tim.

Model kepemimpinan servant juga cocok dipergunakan oleh perawat yang mempunyai pekerjaan sebagai Helper (penolong) untuk siap, dan tanggap dalam menolong pasien. Pelayanan bermutu yang berorientasi pada kebutuhan pelanggan. Menurut Waterman (2011), bahwa kelebihan menggunakan model kepemimpinan servant adalah memperlakukan orang lain sebagai ujung tombak, memungkinkan orang lain untuk berkembang, menunjukkan komitmen terhadap masyarakat, pendekatan interpersonal, penggunaan caring, memfasilitasi bukan otoritas, meningkatkan kinerja staf.

Faktor yang paling dominan memengaruhi kinerja adalah model kepemimpinan sedangkan faktor karakteristik individu tidak berhubungan. Sesuai dengan penelitian yang dilakukan oleh Didimus, et al. (2013), bahwa faktor-faktor yang berhubungan dengan kinerja perawat, ada hubungan antara kepemimpinan, pelatihan, rekan kerja, kondisi kerja, pengakuan, dan sistem imbalan. Penelitian Natalia (2010), memaparkan bahwa model kepemimpinan diwakili oleh kepemimpinan transformasional yang memengaruhi komunikasi, kolaborasi dan keutuhan tim (kerja sama tim) dan kinerja waktu proyek. Hasil penelitian ini mendukung pendapat bahwa model kepemimpinan memengaruhi kinerja perawat pelaksana. Kinerja perawat pelaksana yang masih kurang baik menuntut manajer untuk mengupayakan peran dan fungsinya secara optimal. Memahami hubungan antara model kepemimpinan dengan kinerja perawat adalah penting untuk meningkatkan kinerja perawat. Menggunakan model kepemimpinan servant atau menggabungkan model servant, visioner, dan transaksional berhubungan 
dengan kinerja perawat. Keterbatasan penelitian ini hanya dilakukan di satu rumah sakit pemerintah, belum dilakukan penelitian di rumah sakit swasta dan militer. Penelitian hanya menggunakan instrumen persepsi perawat pelaksana dan belum disertai dengan observasi.

\section{Kesimpulan}

Tidak ada hubungan karakteristik responden umur, jenis kelamin, pendidikan, status perkawinan, lama kerja dengan kinerja perawat pelaksana di rumah sakit. Sedangkan, ada hubungan model kepemimpinan servant, visioner, dan transaksional, kepala ruangan dengan kinerja perawat pelaksana di rumah sakit. Selain itu, tidak ada hubungan model kepemimpinan situasional dan transformasional kepala ruangan dengan kinerja perawat pelaksana. Model kepemimpinan servant yang paling dominan berhubungan dengan peningkatan kinerja perawat pelaksana di Rumah sakit.

Saran bagi pelayanan keperawatan membuat kebijakan tentang metode kepemimpinan kepala ruangan menggunakan servant. Membuat acuan peran dan fungsi kepala ruangan berdasarkan model kepemimpinan servant. Saran bagi pendidikan keperawatan dengan menambah materi model kepemimpinan, dan kinerja perawat. Saran bagi penelitian selanjutnya dengan metode kuasi eksperimen, dan melakukan replikasi penelitian di rumah sakit swasta dan militer.

Penelitian ini menunjukkan adanya hubungan yang signifikan antara kepemimpinan servant dengan kinerja perawat pelaksana. Temuan ini dapat dijadikan sebagai masukan bagi pimpinan rumah sakit untuk memfasilitasi kepala ruangan dalam meningkatkan penerapan kepemimpinan servant. Selain itu, diharapakan rumah sakit dapat mengimplementasikan model kepemimpinan servant yang mempunyai daya ungkit meningkatkan kinerja perawat pelaksana. Kepala ruangan menggunakan model kepemimpinan servant melalui elemen-elemen dalam menjalankan peran dan fungsinya. Pe- nelitian ini dapat dijadikan evidance based practiced untuk mengembangkan ilmu keperawatan khususnya manajemen keperawatan (INR, RR, TN).

\section{Ucapan Terima Kasih}

Direktur, Bagian Sumber Daya Manusia, Bagian Pendidikan dan Penelitian, dan Bidang Keperawatan RSAB Harapan Kita yang telah memberi bantuan baik berupa financial maupun nonfinancial. Direktur, Bagian Penelitian dan Pengembangan, Bidang Keperawatan, dan Komite Keperawatan RS Kanker Dharmais atas kesempatan dan bantuan untuk uji coba instrumen penelitian.

\section{Referensi}

Ahmad, M. (2012). Analisis manajemen mutu terpadu (TQM) dalam pelaynan rumah sakit (Jurnal Artikel Riset Dosen). Gorontalo: Universitas Negeri Gorontalo. Retrieved from http://repository.ung.ac. id/hasilriset/show/1/116/analisis-manajem en-mutu-terpadu-tqm-dalam-pelayanan-r umah-sakit.html

Al-Ahmadi, H. (2009). Factors affecting performance of hospital nurses in Riyadh Region, Saudi Arabia. International Journal of Health Care Quality Assurance, 22 (1), 40-54. doi: http://dx.doi.org/10. 1108/09526860910927943.

Alfian, M.A. (2009). Menjadi pemimpin politik. Jakarta: PT. Gramedia Pustaka Utama.

Bastable, S.B. (2002). Nurse educator: Principle of teaching and learning (Perawat sebagai pendidik prinsip-prinsip pengajaran dan pembelajaran). (Alih bahasa: G. Wulanari \& G. Widiyanto). Jakarta: Penerbit Buku Kedokteran EGC.

Bidang Keperawatan RSAB Harapan Kita. (2014). Laporan tahunan bidang keperawata RSAB Harapan Kita (Laporan, tidak dipublikasikan). Jakarta: RSAB Harapan Kita. 
Didimus, I.S., Indar, I., \& Hamzah, A. (2013). Faktor yang berhubungan dengan kinerja perawat di ruang rawat inap rumah sakit ibnu sina YBW-UMI Makasar. Jurnal Universitas Hasanuddin. Retrieved from http:// repository. unhas.ac.id/ bitstream/ handle/123456789/5747/JURNAL.pdf?seq uence $=1$

Fitrihana, N. (2011). Peningkatan daya saing produk melalui fungsi-fungsi manajemen sumber daya manusia. Yogyakarta: Fakultas Teknik Universitas Negeri Yogyakarta.

Goleman, D., Boyatzis, R., \& McKee, A. (2007). Emotional inteligence. Jakarta: Gramedia Pustaka Utama.

Heller, R. (2008/2001). Steven Covey: Guru paling laris yang mengajarkan efektifitas pribadi dan professional (Alih bahasa: Irzam Hardiansyah). Jakarta: Erlangga.

Hewison, A., \& Griffiths, M. (2004). Leadership development in health care: A word of caution. Journal of Health Organization and Management, 18 (6), 464-473.

Ilyas, Y. (2012). Kinerja teori, penilaian \& penelitian (edisi revisi). Depok: Fakultas Kesehatan Masyarakat Universitas Indonesia.

Kementerian Kesehatan RI. (2013a). Petunjuk pelaksanaan jenjang karir perawat di rumah sakit. Jakarta: Kementerian Kesehatan RI.

Kementerian Kesehatan RI. (2013b). Pedoman remunerasi perawat di rumah sakit. Jakarta: Kementerian Kesehatan RI.

Kieu, H.Q. (2010). Leadership styles and organizational performance: A predictive analysis (3442746 D.M.). University of Phoenix, Ann Arbor. Retrieved from http://search.proquest.com/docview/85364 1823 ? accountid=17242ABI/INFORM
Kuspriyomurdono, S. (2012). Penilaian prestasi kerja pegawai negeri sipil. Jakarta: Badan Kepegawaian Negara.

Mahembe, B., \& Engelbrecht, A. S. (2014). The relationship between servant leadership, organisational citizenship behaviour and team effectiveness. SA Journal of Industrial Psychology, 40(1), 1-10. doi:10.4102/sajip.v40i1.1107.

Mamikhani, J., Tofighi, S., Sadeghifar, J., Heydari, M., \& Jenab, V. H. (2014). Prioritizing the Compensation Mechanisms for Nurses Working in Emergency Department of Hospital Using Fuzzy DEMATEL Technique: A Survey from Iran. Global Journal of Health Science, 6(2), 86-93.

Natalia, F. (2011). Analisia kepemimpinan transaksional dan transformasional untuk meningkatkan kerjasama tim dan kinerja waktu proyek. Tesis, tidak dipublikasikan. Jakarta: UI.

Oei, I. (2005). Riset sumber daya manusia: Cara paktis mengukur stress, kepuasan kerja, komitmen, loyalitas, motivasi kerja dan aspek-aspek kerja karyawan lainnya. Jakarta: PT. Gramedia Pustaka Utama.

Robbins, S.P., \& Judge, T.A. (2013). Oragnizational behavior $\left(15^{\text {th }}\right.$ Ed). USA: Prentice Hall.

Robert L. M. \& John H. J. (2006). Human resources management, Edisi sepuluh, Penerbit Salemba Empat

Sari, M. T. (2009). Hubungan budaya organisasi dan gaya kepemimpinan kepala ruangan dengan kinerja perawat pelaksana di ruang rawat inap rumah sakit daerah Raden Mattaher Jambi (Tesis, Program Studi Magister). Depok: Fakultas Ilmu Keperawatan Universitas Indonesia

Setiawati, D. (2010). Determinan kinerja perawat di ruang rawat inap rumah sakit TNI AL Dr Mintohardjo (Tesis, Program Studi Magister). Depok: Fakultas Ilmu Keperawatan Universitas Indonesia 
Sitanggang, L. (2010). Hubungan karakteristik individu kepemimpinan transformasional dan transaksional kepala ruangan dengan kinerja perawat di pk st. carolus Jakarta (Tesis, Program Studi Magister). Depok: Fakultas Ilmu Keperawatan Universitas Indonesia

Tappen, R.M. (2004). Essentials of nursing leadership and management. $3^{\mathrm{rd}} \mathrm{Ed}$. Philadelphia: Davis Company.

Waterman, H. (2011). Principles of 'servant leadership' and how they can enhance practice. Nursing Management, 17(9), 2426.

Wilches-Alzate, G. (2009). The relationship between rewards and recognition, serviceoriented organizational citizenship behaviour, and customer satisfaction.
NR56174 Ph.D., University of Waterloo (Canada), Ann Arbor. Retrieved from http://search.proquest.com/docview/30513 9170? accountid=17242ABI/INFORMCom plete; ProQuest Dissertations \& Theses Global database.

Yasman, Y. (2013). Model kepemimpinan kepala ruangan menurut pandangan perawat pelaksana berhubungan dengan retensi. Jurnal Keperawatan Indonesia 18 (1), 3137. doi: 10.7454/jki.v18i1.395.

Yuswanto, T.J.A. (2013). Pengembangan model kepemimpinan keperawatan di ruang rawat inap rumah sakit kelas $A$ di Indonesia (Tesis, Program Studi Magister). Depok: Fakultas Ilmu Keperawatan Universitas Indonesia. 